\title{
La fiscalidad de las cooperativas ante el nuevo Impuesto sobre Sociedades. Propuestas para una reforma
}

Cooperatives taxation in the eyes of the new Corporate Tax. Proposals for a reform

\author{
Marta Montero Simó 1 \\ Universidad Loyola Andalucía (España)
}

Sumario: 1. Situación en la que se encuentra la fiscalidad de las cooperativas. 2. La necesaria revisión del régimen fiscal de las cooperativas tras la nueva ley del Impuesto sobre Sociedades. 2.1. Medidas del régimen general del impuesto que afectan especialmente a las cooperativas. 2.2. Modificaciones a la Ley 20/1990, de Régimen Fiscal de las Cooperativas, introducidas en la Ley $27 / 2015$, del Impuesto sobre Sociedades. 3. La evolución de la regulación del régimen económico en la legislación cooperativa. 3.1. Nuevos tipos de cooperativas que cuestionan la clasificación de cooperativas protegidas y especialmente protegidas. 3.2. Capital social y pasivo exigible. 3.3. Operaciones con terceros ¿flexibilización de las normas sustantivas? 4. Reformas del régimen fiscal de las cooperativas en territorios forales vascos. El tipo mínimo de gravamen. 5. Conclusiones y propuestas para una reforma. 6. Bibliografía.

Summary: 1 . Nowadays situation of taxation of cooperatives. 2. The necessary review of the taxation of cooperatives after the new Corporate Income Tax law. 2.1. Measures of the tax general regime particularly affecting cooperatives. 2.2. Amendments to Law 20/1990 of Fiscal Regime of Cooperatives, settled by the Act 27/2015 of the Corporate Income Tax. 3. The evolution of regulation of the economic system in cooperative legislation. 3.1. New types of cooperatives which question the classification of protected and specially protected cooperatives. 3.2. Equity and current liabilities. 3.3. Transactions with non-members, are flexible substantive rules? 4. Reforms of the taxation of cooperatives in Basque territories. The minimum tax rate. 5. Conclusions and proposals for reform. 6. Bibliography.

1 Profesora titular de Derecho Financiero y Tributario. Correo electrónico: mmontero@uloyola.es 
Resumen: La Ley 27/2014, del Impuesto sobre Sociedades ha introducido medidas como la reducción del tipo de gravamen general, la modificación del porcentaje de participación del socio en la sociedad para determinar el perímetro de vinculación, las reducciones por destinar resultados a fondo de capitalización o a fondo de nivelación, entre otras, que demandan una adaptación del régimen fiscal de las cooperativas al nuevo Impuesto sobre Sociedades. A lo que se unen las reformas operadas en las leyes cooperativas desde 1990. En el presente artículo se realiza una revisión de los mencionados cambios y se proponen posibles reformas al régimen fiscal vigente, atendiendo a su contenido esencial, el relativo al Impuesto sobre Sociedades.

Palabras clave: Fiscalidad, cooperativas, Impuesto sobre sociedades, beneficios fiscales

Abstract: The Act 27/2014, on Corporate Income Tax has introduced measures as the reduction of the tax rate, the amendment of the percentage of participation of the partner in the company in related-party transactions, the reductions in the tax base fund of capitalization and fund of leveling, between others, which demand adjustment of the fiscal regime of the cooperatives to the new regulation. It there join the reforms undertaken in the many cooperative laws from 1990. In the present article there is a review of the mentioned changes and there are reform proposals concerning cooperatives tax system, attending to his essential content, the relative one to the Corporate Income Tax. tives

Key words: Taxation, cooperatives, Corporation Income Tax, tax incen- 


\section{Situación en la que se encuentra la fiscalidad de las cooperativas}

La existencia de un régimen fiscal específico para determinado tipo de sociedades sólo puede responder a que dichas sociedades presenten diferencias estructurales respecto a las sociedades a las que se le aplican las normas generales y que por lo tanto, deban establecerse normas especiales, que adapten las generales a estas entidades.

Si leemos la exposición de motivos de la Ley 20/1990, de 19 de diciembre, sobre Régimen Fiscal de las Cooperativas, comprobaremos que los motivos por los que se acometió la reforma del régimen fiscal de estas sociedades en 1990, son idénticos a los que hoy nos animan a defender la necesaria revisión del régimen fiscal vigente. "Las profundas modificaciones experimentadas por el régimen jurídico sustantivo de las cooperativas, después de la aprobación de la Ley 3/1987, de 2 de abril, General de Cooperativas y de diversas leyes autonómicas...» así como las experimentadas por el sistema tributario «a raíz de la reforma fiscal iniciada por la Ley de Medidas Urgentes de 14 de noviembre de 1977 hacen absolutamente necesaria la promulgación de una nueva legislación sobre el régimen fiscal de las cooperativa sustitutiva de la vigente, la cual, ....adolece básicamente de una importante falta de adecuación a la nueva realidad jurídica de las cooperativas y del sistema tributario, lo que complica y dificulta el cumplimiento de las obligaciones tributarias a este tipo de entidades».

Sorprende que, desde enero de 1991, el régimen fiscal de las cooperativas en España no haya experimentado modificaciones importantes. Junto a adaptaciones consecuencia de cambios operados en la ley del Impuesto sobre Sociedades y en la ley del Impuesto sobre la Renta de las Personas Físicas, como son la eliminación de la deducción para eliminar la doble imposición cooperativa-socio persona física o la limitación cuantitativa en la compensación de cuotas negativas, se han realizado, en nuestra opinión, sólo dos modificaciones que obedecen a otros motivos. En 1995 se incluyó a las cooperativas agrarias, entre las cooperativas a las que no se les aplicaba la norma de valor de mercado en las operaciones que realizan con socios y en 2011 se suprimió la posibilidad que tenían, también las cooperativas agrarias, de vender gasóleo tipo $B$ a terceros de forma ilimitada sin perder la condición de cooperativa protegida, ni la de especialmente protegida. Esta segunda medida vino impuesta en 2009 por la Deci- 
sión de la Comisión Europea en aplicación del régimen de ayudas de Estado².

Si tenemos en cuenta las modificaciones que ha experimentado desde 1990 la regulación jurídico sustantiva de las cooperativas, tanto en la ley estatal como en las ya, dieciséis, leyes autonómicas y la reforma del Impuesto sobre Sociedades materializada en la Ley 27/2014, de 27 de noviembre, es evidente que se han producido cambios significativos tanto en las peculiaridades que justificaban en 1990 las normas de ajuste como en la normas del Impuesto sobre Sociedades que deben ser «ajustadas» ${ }^{3}$.

Entre los «objetivos» sobre los que se asienta el nuevo Impuesto sobre Sociedades, tienen especial incidencia a la hora de considerar la reforma del régimen fiscal de las cooperativas, el objetivo de «neutralidad, igualdad y justicia», y el de «necesaria adaptación al Derecho comunitario». Se persigue que el impuesto no genere alteraciones sustanciales en el comportamiento empresarial, para lo que se adoptan medidas como la aproximación del tratamiento fiscal de la financiación ajena y propia, la aproximación entre el tipo de gravamen nominal y efectivo o la eliminación de beneficios fiscales ${ }^{4}$.

2 Respecto a la Decisión de la Comisión (C22/2001, de 14 de Diciembre de 2009) y su impacto sobre la Ley de Régimen Fiscal de las cooperativas españolas, véase entre otros (Tejerizo López 2010, 60-65) (Alguacil Mari 2010, 37) y (Arana Landin 2011, 77-98).

3 (Paniagua Zurera y Jiménez Escobar 2014: 87-88) ponen de manifiesto con acierto, el mencionado distanciamiento entre el modelo de cooperativa vigente en 1990 y la realidad de la regulación cooperativa vigente: "La normativa aplicable a las cooperativas en España es disfuncional ya que provoca una serie de efectos indeseables -y comentamos los principales - en el seno de cualquier ordenamiento: $\left.1 .^{\circ}\right)$ El contrasentido de que la Ley de Cooperativas (de 1999, formalmente vigente y con un modelo cooperativo economicista atemperado) haya quedado casi sin eficacia real pues resulta aplicable, en la mayoría de las ocasiones, la legislación autonómica. $2^{\circ}{ }^{\circ}$ Por su parte, la legislación tributaria vigente tiene como paradigma el modelo cooperativo de la ley estatal de 1987 (con un modelo social atemperado), con lo que está presidida por un modelo de sociedad cooperativa ya prácticamente inexistente en la realidad española. El resultado final es una contradicción entre la legislación de naturaleza tributaria y la legislación sustantiva realmente aplicable, provocando que actos u omisiones admitidos en la legislación sustantiva Estatal o autonómica no sean admitidos, so pena de perder los beneficios fiscales, por la legislación tributaria. $3^{\circ} .^{\circ}$ La paradoja de que una normativa de naturaleza adjetiva (la tributaria en este caso) sea la que está homogeneizando en la práctica, al ser la que tienen presente las sociedades cooperativas con el objeto de no perder los beneficios fiscales, elementos esenciales de la organización y el régimen económico de la sociedad cooperativa, lo que indudablemente debería constituir una tarea que corresponde a la legislación sustantiva».

4 Ambos expresamente previstos en la Exposición de motivos de la Ley 27/2014, del Impuesto sobre Sociedades. 
Sin lugar a dudas, la legislación cooperativa, la regulación del Impuesto sobre Sociedades y del Impuesto sobre la Renta, la prohibición de la Unión Europea en materia de ayudas de Estado y el artículo 129.2 de la Constitución española constituyen el marco normativo delimitador y condicionante de la fiscalidad de las cooperativas.

Finalmente, es importante señalar como una cara más de ese marco pluridimensional que condiciona una reforma, el reconocimiento que las cooperativas reciben en la Unión europea. Son varios los documentos en los que reconoce su función económica y social y se destaca el papel que desempeña como agente colaborador de la Unión Europea en la consecución de los objetivos comunitarios ${ }^{5}$. La Comisión en 2004 ya invitaba a los Estados miembros a que atendieran a la naturaleza específica del capital de las cooperativas y a la de las reservas, debiendo respetar el principio de proporcionalidad de los beneficios concedidos a las limitaciones jurídicas, al valor social añadido o a las limitaciones inherentes a la fórmula cooperativa, evitando crear una fuente de competencia desleal ${ }^{6}$.

\section{La necesaria revisión del régimen fiscal de las cooperativas tras la Ley del Impuesto sobre Sociedades}

\subsection{Medidas del régimen general del impuesto que afectan especialmente a las cooperativas}

La Ley 27/2014, de 27 de noviembre, del Impuesto sobre Sociedades, declara expresamente vigentes la Ley de Régimen Fiscal de las Sociedades Cooperativas, la Ley de Régimen Fiscal de las Entidades sin Fines Lucrativos y del Mecenazgo y la Ley Reguladora del Régimen Fiscal

5 Según la Comisión Europea, las cooperativas constituyen un ejemplo excelente de un tipo de empresa que responde simultáneamente a objetivos empresariales y sociales, de forma que estos se refuerzan mutuamente. Además, en el ámbito de la política de empresas, considera que las cooperativas desempeñan una función importante en la economía agrícola, para el desarrollo de regiones con dificultades económicas, en las que la estructura cooperativa resulta ideal para fomentar el empleo y la cohesión social.

La Comisión exhorta a que se divulgue la función y el potencial de las cooperativas, no solo por los beneficios inmediatos para las propias cooperativas, sino también por su vinculación con importantes políticas y objetivos. Véase Comunicación de la Comisión al Consejo, al Parlamento Europeo, al Comité Económico y social europeo y al Comité de las Regiones sobre el fomento de las cooperativas en Europa. Bruselas, 23.2.2004, COM (2004) 18 final.

6 Véase (Montero Simó 2007, 627-684). 
de las Sociedades Anónimas Cotizadas de Inversión en el Mercado Inmobiliario; si bien introduce dos modificaciones de poco calado en la Ley 20/1990.

Al ser de aplicación a las sociedades cooperativas con carácter subsidiario, el régimen general del Impuesto, la reforma llevada a cabo en el mismo también afecta a las cooperativas; pero no sólo eso, el hecho de no reformar el régimen fiscal especial de estas sociedades, implica ya indirectamente una reforma. El caso más llamativo lo tenemos en la existencia de un tipo de gravamen reducido aplicable a los resultados cooperativos que se mantiene en un $20 \%$, mientras el tipo general del Impuesto se ha visto reducido de un $35 \%$, en 1990 a un $25 \%$ tras la reforma operada en 2014.

\section{a) Prevalencia de la calificación juRídico mercantil sobre la contable}

El Plan General Contable de 2007 introdujo una novedad importante en relación con la contabilización de algunos instrumentos que venían considerándose instrumentos de patrimonio, en coherencia con la calificación mercantil, y que tenían una naturaleza muy próxima a los pasivos financieros. En concreto nos referimos a las acciones rescatables. Estos instrumentos pasaron a ser calificados desde el punto de vista contable, como pasivos financieros por dos motivos que los diferenciaban de las acciones ordinarias. Por una parte, el accionista tenía derecho a exigir el rescate o la sociedad la obligación de realizarlo y por otra, el accionista no adquiría estas acciones con vocación de permanencia en la sociedad, ni de participación en la gestión.

Estas acciones rescatables presentan cierto paralelismo con las participaciones de los socios en sociedades cooperativas. En el caso del capital de las cooperativas debido al carácter reembolsable de sus participaciones, directamente relacionado con el principio cooperativo de puertas abiertas, la CINIIF 2. Sobre aportaciones de socios de entidades cooperativas e instrumentos similares, reconoce en sus precedentes que «resulta difícil la aplicación de los criterios recogidos en la NIC 32» y establece que «las aportaciones de los socios serán considerados patrimonio neto si la entidad tiene derecho incondicional a rechazar el rescate (apartado 7). No obstante lo anterior, la prohibición incondicional podría ser absoluta de manera que los rescates están prohibidos, o podría ser parcial, de manera que se vete el rescate de las aportaciones de los socios si el mismo diese lugar a que el número de aportaciones o el capital desembolsado que representan cayese por debajo de un determinado nivel. En este caso, las aportaciones de los socios por encima 
del nivel a partir del cual se aplique la prohibición de rescate serán pasivo».

A partir de 2007, para evitar que el capital de la cooperativa fuera calificado como pasivo exigible, fueron muchas las leyes cooperativas que modificaron el derecho de reembolso por baja de los socios ${ }^{7}$, creándose un nuevo tipo de participaciones no reembolsables. El cambio en la legislación cooperativa se produjo ante el miedo a las posibles dificultades para acceder a la financiación ajena, entre otras consecuencias derivadas del cambio de calificación.

¿Qué consecuencias tuvo sobre la tributación de los rendimientos de los cooperativos? ¿Se calificaron de distinta forma tanto en el Impuesto sobre Sociedades de la sociedad como en el Impuesto sobre la Renta del socio, estos rendimientos cuando procedían de participaciones reembolsables y no reembolsables respectivamente? ¿Se admitió la deducibilidad para la cooperativa de los retornos cooperativos directamente relacionados con las participaciones reembolsables, al ser calificadas desde 2007 contablemente como pasivo exigible?

El artículo 10.3 del antiguo Texto Refundido que regulaba el Impuesto sobre Sociedades establecía que en aplicación del método de estimación directa, "la base imponible se calculará corrigiendo, mediante la aplicación de los preceptos establecidos en esta Ley, el resultado contable determinado de acuerdo con las normas previstas en el Código de Comercio, en las demás leyes relativas a dicha determinación y disposiciones que se dicten en desarrollo de las citadas normas». En consecuencia, se tenía que admitir la deducibilidad de los gastos financieros que generaran los pasivos financieros de los que venimos hablando. Los dividendos satisfechos a accionistas titulares de acciones rescatables eran deducibles, debiendo cumplir con los requisitos relativos a la imputación del gasto y sometidos a la limitación relativa a la

7 En 2008 se modificó la Ley 27/1999, de cooperativas de Estado, previendo en su artículo 45 lo siguiente:

1. El capital social estará constituido por las aportaciones obligatorias y voluntarias de los socios, que podrán ser:

a) aportaciones con derecho de reembolso en caso de baja.

b) aportaciones cuyo reembolso en caso de baja pueda ser rehusado incondicionalmente por el Consejo Rector.

La transformación obligatoria de las aportaciones con derecho de reembolso en caso de baja en aportaciones cuyo reembolso pueda ser rehusado incondicionalmente por el Consejo Rector, o la transformación inversa, requerirá el acuerdo de la Asamblea General, adoptado por la mayoría exigida para la modificación de los estatutos. El socio disconforme podrá darse de baja, calificándose ésta como justificada. 
deducibilidad de los gastos financieros ${ }^{8}$, realidad que era extensible a los retornos cooperativos relativos a participaciones reembolsables. Por lo tanto, desde la entrada en vigor de la mencionada norma del Plan General de Contabilidad en 2011 hasta 2014, las cooperativas podían considerar los retornos cooperativos, relativos a aportaciones a capital reembolsables, gastos cooperativos deducibles.

No hubo ninguna reacción del legislador y la Ley 20/1990 de régimen fiscal de las cooperativas, mantuvo silencio, por lo que no se pasaron a reconocer los retornos cooperativos (en el supuesto planteado) entre los gastos cooperativos previstos en su artículo 18.3, en el que se prevén entre otros gastos, expresamente, los intereses pagados a socios y asociados por sus aportaciones obligatorias y voluntarias a capital social. En nuestra opinión, la calificación de dicho gasto sería la de gasto cooperativo, al tratarse de la remuneración de un pasivo exigible con socios.

La Ley 27/2014 reguladora del Impuesto sobre Sociedades, introduce un cambio importante en su artículo 15 en el que regula los gastos no deducibles. Se trata de un paso hacia atrás respecto a la aplicación del principio básico de prevalencia del fondo sobre la forma, presente en la norma contable. Define de forma expresa la retribución a fondos propios como la correspondiente a «los valores representativos del capital o de los fondos propios de entidades, con independencia de su consideración contable» y pasa a prohibir en el apartado a) de dicho artículo 15, la deducibilidad de los gastos que representen retribución a fondos propios.

El artículo 15 de la Ley 27/2014 se aparta del criterio contable y por lo tanto, de la norma general prevista en el artículo 10.3 de esa misma Ley y excluye la deducibilidad de la retribución a las acciones sin voto o acciones rescatables, consideradas contablemente como pasivos financieros, así como la deducibilidad de los retornos satisfechos a aportaciones reembolsables, en casos de baja o separación del socio de la cooperativa.

Pensamos que el cambio operado no ha tenido presente el tratamiento de los retornos cooperativos, máxime existiendo una norma

8 Así se pone de manifiesto en la Consulta Tributaria V0991-14. La entidad consultante había distribuido anualmente desde 2008 un dividendo mínimo a una determinada serie de participaciones sin derecho a voto, a las que les corresponde el $5 \%$ sobre el nominal con independencia del dividendo ordinario que en su caso les pudiera corresponder. La entidad había contabilizado, por error esos dividendos como el resto. La Administración tributaria admite la deducibilidad en el supuesto en que la entidad los contabilice como gastos, imputándolos a un ejercicio posterior a aquél en el que se generaron. 
específica reguladora del régimen fiscal de las cooperativas que se entiende debe regular aquello que es específico de la cooperativa. Recobra especial interés el artículo 18.3 de la Ley 20/1990, en el que se prevé la deducibilidad de los intereses satisfechos por la cooperativa a los socios y asociados por sus aportaciones obligatorias y voluntarias al capital social, siempre que el interés no exceda del básico del Banco de España incrementado en tres puntos para los socios y cinco puntos para asociados ${ }^{9}$. Claramente se trata de una excepción a la prohibición introducida en el artículo 15 de la Ley del Impuesto sobre Sociedades, de la deducibilidad de la retribución de fondos propios que ¿debería extenderse a los retornos satisfechos por aportaciones reembolsables en caso de baja o separación del socio?

\section{b) ReducCiÓN DEL PERÍMETRO de VINCULACIÓN EN LA REGULACIÓN DE OPERACIONES VINCULADAS}

El artículo 15 de la Ley 20/1990 contempla una norma de valoración, mediante la que se adapta la regulación prevista con carácter general en el Impuesto sobre Sociedades para las operaciones vinculadas, a las operaciones que la cooperativa realiza con sus socios. Establece como norma general, que las operaciones que la cooperativa realiza con sus socios deberán valorarse a valor de mercado, como si se tratara de una operación más realizada entre sujetos vinculados.

Es cierto que el mismo artículo 15 pasa a establecer excepciones a esa norma general, que justifican que hablemos de una norma de

9 Artículo 48 de la Ley 27/1999, de Cooperativas del Estado. «Remuneración de las aportaciones.

1. Los Estatutos establecerán si las aportaciones obligatorias al capital social dan derecho al devengo de intereses por la parte efectivamente desembolsada, y en el caso de las aportaciones voluntarias será el acuerdo de admisión el que fije esta remuneración o el procedimiento para determinarla.

2. La remuneración de las aportaciones al capital social estará condicionada a la existencia en el ejercicio económico de resultados positivos previos a su reparto, limitándose el importe máximo de las retribuciones al citado resultado positivo y, en ningún caso, excederá en más de seis puntos del interés legal del dinero.

3. En la cuenta de resultados se indicará explícitamente el resultado antes de incorporar las remuneraciones a que se ha hecho referencia en los puntos anteriores, y el que se obtiene una vez computadas las mismas.

4. Si la Asamblea General acuerda devengar intereses para las aportaciones al capital social o repartir retornos, las aportaciones previstas en el artículo 45.1.b) de los socios que hayan causado baja en la cooperativa y cuyo reembolso haya sido rehusado por el Consejo Rector, tendrán preferencia para percibir la remuneración que se establezca en los estatutos, sin que el importe total de las remuneraciones al capital social pueda ser superior a los resultados positivos del ejercicio». 
ajuste. Las operaciones realizadas por las cooperativas de consumidores y usuarios, de viviendas, agrarias y cualquiera, que conforme a sus estatutos realicen servicios o suministros a socios, computaran al precio por el que efectivamente se hubieran realizado, admitiendo que dicho precio sea distinto al de mercado y siempre que no sea inferior al coste de tales servicios o suministros. En el caso de las cooperativas agrarias se aplicará dicha limitación también para los servicios que la cooperativa realice a sus socios.

Realmente, el valor de mercado solo es exigible respecto a los anticipos laborales y a las operaciones de prestación de servicios o entregas de bienes de los socios a la cooperativa, excepto a las cooperativas agrarias.

Sin embargo, desde el punto de vista contable, la Orden EHA/3360/2010, de 21 de diciembre, por la que se aprueban las normas sobre los aspectos contables de las sociedades cooperativas, admite que las operaciones que la cooperativa realiza con socios no se identifican como transacciones entre partes vinculadas. Pone de manifiesto en su introducción que «El precio de los bienes y servicios que socio y sociedad intercambian están fijados en su conjunto en términos de valor de mercado siempre que la lógica económica presente en la actividad de la cooperativa ponga de manifiesto que su objeto social se configura como medio para canalizar la actividad del cooperativista en el mercado y, en consecuencia, que en el citado contexto, un mercado singular, los citados precios constituyen la mejor estimación del valor razonable de estas operaciones. En este sentido, la mayoría de las leyes autonómicas establecen como límite del precio que puede abonar la cooperativa al cooperativista el propio precio de mercado o de liquidación frente a terceros, asumiendo que la lógica del ánimo de lucro inherente a cualquier actividad empresarial y el correspondiente valor añadido, en estos casos, se desplaza de la sociedad al cooperativista».

Como indican Polo Garrido y Sarasa Cortina, con ello las normas han venido por un lado, a reconocer la existencia de unos precios internos (precios de liquidación) y por otro, a conciliarlos con el valor razonable del llamado por la norma contable «mercado singular» que constituye la cooperativa ${ }^{10}$. Estas transacciones no se identifican como transacciones entre partes vinculadas.

La reforma operada en la ley 27/2014, del Impuesto sobre Sociedades, sobre el perímetro de vinculación y más en concreto, el incremento del porcentaje de participación exigido al socio, para que se considere la

10 Ver (Polo Garrido y Sarasa Cortina 2013: 87-107). 
operación como operación vinculada, que se incrementa de un $5 \%$ a un $25 \%$, junto al reconocimiento de la norma contable, de que nos hallamos ante operaciones que quedan fuera del ámbito de las operaciones vinculadas, hace que nos cuestionemos la norma de valor de mercado para las operaciones que comportan un gasto para la cooperativa.

Son varias las dudas relacionadas con este tema, que nos suscita la reforma operada en el Impuesto sobre Sociedades:

Si se aplica el artículo 15 de la Ley 20/1990, a las cooperativas de segundo y ulterior grado y por lo tanto cualquier operación que realicen con socios que comporte un gasto para la cooperativa, se valora a valor de mercado ino existe un trato discriminatorio respecto a las operaciones que esa misma cooperativa realiza con sociedades mercantiles a las que se aplicará el artículo 18 de la Ley del Impuesto sobre Sociedades y por lo tanto, solo serán partes vinculadas cuando la participación sea del $25 \%$ ?

¿A cualquier operación realizada por la cooperativa y sus socios al margen del desarrollo de sus fines sociales, se le aplica el art. 18 de la ley del impuesto sobre sociedades y por lo tanto el requisito de participación del $25 \%$ ?

¿No están obligados los socios a realizar operaciones económicas con la cooperativa a diferencia de lo que ocurre con las sociedades mercantiles en las que la realización de operaciones es casual? ${ }^{11}$.

En definitiva, ¿qué sentido tiene mantener una norma que no deja de ser una norma anti elusión para las operaciones que la cooperativa realiza con los socios que además, es más desfavorable que la prevista en el régimen general cuando la razón de ser de las cooperativas es realizar operaciones con sus socios? Recordemos que las leyes cooperativas sustantivas no limitan el valor de la operación salvo en contadas excepciones.

\section{C) Aproximación del tRATAMIENTO fiscAl de LA DEUdA Y DEL CAPITAL. REDUCCIONES POR CREACIÓN DE FONDO DE RESERVA DE CAPITALIZACIÓN Y FONDO DE NIVELACIÓN}

La nueva Ley del Impuesto sobre Sociedades ha introducido dos incentivos fiscales vinculados al incremento del patrimonio neto, uno en

11 (Arana Landín 2010: 145) afirma, en este sentido, «nos planteamos si no resulta extraño a la naturaleza mutual esta obligación de aplicar el valor de mercado»... «tal vez hay que hacerse la pregunta de si tiene sentido la diferencia de valoración de los productos entre socio y cooperativa dependiendo del tipo de cooperativa de que se trata o, si por el contrario, dicha excepción debería resultar con carácter general». 
el régimen general y otro, en el régimen de empresas de reducida dimensión. Se trata respectivamente, de la reducción por reserva de capitalización y la reducción por fondo de nivelación. Ambos incentivos sustituyen a otros dos incentivos previstos en el Impuesto, la deducción por reinversión y la deducción por inversión de beneficios, aplicable esta última exclusivamente a las empresas de reducida dimensión.

El objetivo de las dos deducciones que han sido suprimidas, era incentivar la capitalización de la sociedad. En ambas se exigía la inversión en elementos nuevos de inmovilizado material o inversiones inmobiliarias, todos ellos afectos a la actividad económica de la sociedad. También se requería en ambos casos el mantenimiento de la inversión en un plazo de 5 años.

La deducción por inversión de beneficios no era aplicable a las cooperativas protegidas y especialmente protegidas por disfrutar éstas de un tipo reducido aplicable a los resultados cooperativos. Se trataba de una forma de evitar que disminuyera el tipo efectivo de las cooperativas, al disfrutar éstas de un tipo ya reducido.

Las nuevas reducciones persiguen potenciar la capitalización empresarial mediante el incremento del patrimonio neto, e incentivar el saneamiento de las empresas ${ }^{12}$, sin necesidad de que se lleven a cabo inversiones específicas. Además tratan de aproximar el tratamiento fiscal de la financiación ajena frente a la financiación propia.

La reducción por reserva de capitalización es aplicable a los contribuyentes que tributen a los tipos previstos en los números 1 y 6 del artículo 29 de la ley del Impuesto sobre Sociedades. Las cooperativas protegidas y especialmente protegidas tributan según lo previsto, en el número 2 del artículo 29, al 20\%, excepto los resultados cooperativos que tributan al tipo general. Por lo tanto la reducción no es aplicable a cooperativas que disfruten de la condición de protegidas o especialmente protegidas, pero sí lo es para las cooperativas que tributen al tipo general. Exactamente igual ocurre con la reducción por reserva de nivelación.

Entendemos que el motivo por el cual se ha excluido de la aplicación de esta reducción a las cooperativas es el hecho de que los resultados que se podrían destinar temporalmente a la reserva de capitalización, tributen al $20 \%$. Al respecto hay que decir, en primer lugar, que no van a tributar necesariamente, a un tipo reducido, ya que si se trata de resultados extracooperativos (no todas las leyes cooperativas obli-

12 Tal y como se indica en la exposición de motivos de la Ley $27 / 2014$, del Impuesto sobre Sociedades. 
gan a destinar el $100 \%$ de los resultados extracooperativos, a fondos de reserva obligatorios) tributan al tipo general y además, aun tratándose de resultados cooperativos el tipo efectivo se vería reducido tan sólo a un $18 \%$.

Si tenemos en cuenta, que las cooperativas mantienen el tipo del $20 \%$ desde 1990, cuando el tipo general era un 35\% y éste se ha reducido a un 25\%; permitir que disfrutaran de este incentivo implicaría reducir el tipo efectivo, lo que estaría justificado en términos comparativos, y además se fomentaría la capitalización.

Respecto a la aplicación de la reducción por reserva de nivelación, que supone un diferimiento de impuesto, se niega a las cooperativas. Entendemos que de mantener la compensación en cuota, se puede entender que se está anticipando de alguna manera, la compensación de resultados negativos con positivos de distinta naturaleza, al permitir compensar cuotas integras extracooperativas y cooperativas, entre sí. Quizás este haya sido el motivo por el que se ha excluido de su aplicación a las cooperativas.

Sin lugar a dudas, su aplicación para las cooperativas requeriría de una norma de ajuste, pero, entendemos, sería una oportunidad para permitir a las cooperativas de reducida dimensión, disfrutar de todos los beneficios fiscales de los que disfrutan el resto de entidades que reciben la misma calificación.

d) SustituCiÓN DE LA DEDUCCIÓN POR DOBLE IMPOSICIÓN DE DIVIDENDOS DE FUENTE INTERNA POR LA EXENCIÓN POR DIVIDENDOS

El artículo 21 de la ley del Impuesto sobre Sociedades, prevé una exención para evitar la doble imposición de dividendos, tanto de fuente extranjera como de fuente interna, exigiéndose que la participación sea al menos del $5 \%$ o bien que el valor de la participación supere 20 millones de euros. La exención por dividendos de fuente interna sustituye la deducción por doble imposición de dividendos que preveía el artículo 30 del Real Decreto Legislativo 4/2004, de 5 de marzo, por el que se aprueba el texto refundido de la Ley del Impuesto sobre Sociedades

Sin embargo la ley 20/1990 mantiene en su artículo 25 la deducción por doble imposición de retornos cooperativos. La deducción es del $10 \%$ del retorno para socios de cooperativas protegidas, y del $5 \%$ para socios de cooperativas especialmente protegidas. Ello implica que la cooperativa socia pueda deducir tan sólo el $50 \%$ del gravamen que soporta por la percepción del retorno, lo que implica una adaptación de la ya derogada deducción por doble imposición de dividendos de fuente interna. 
Sin lugar a dudas carece de sentido que se elimine totalmente la doble imposición entre dos sociedades de capital, cuando la participación supere un $5 \%$ y no se elimine la doble imposición entre dos cooperativas, sea cual fuera la participación.

¿Es posible mantener esta diferencia de trato sin vulnerar el principio de igualdad?

e) Aproximación del tipo general del impuesto al tipo efectivo:

REDUCCIÓN DEL TIPO GENERAL A UN 25\% Y ELIMINACIÓN DE DEDUCCIONES

El tipo de gravamen general del Impuesto sobre Sociedades se ha reducido de un $30 \%$ a un $25 \%$, eliminándose el tipo reducido aplicable a empresas de reducida dimensión, al equipararse el general a éste. La reducción del tipo general va unida a un ensanchamiento de la base imponible con medidas como la limitación de la deducción de gastos financieros, la prohibición de deducción de ciertos gastos o la limitación en la compensación de bases imponibles negativas, entre otras. A ello hay que unir la eliminación de algunas deducciones. Todo ello provoca que finalmente el tipo efectivo de gravamen no se vea reducido en misma proporción que el tipo nominal.

El problema es que las cooperativas han visto ensanchada su base imponible al aplicarse con carácter subsidiario, el régimen general del impuesto, han visto reducidas las deducciones aplicables, no pueden disfrutar de nuevos incentivos, como son la reducción por reserva de capitalización y por reserva de nivelación, precisamente por disfrutar de un «tipo incentivado» del $20 \%$, exclusivo para resultados cooperativos que no se ha reducido desde 1990.

\subsection{Modificaciones a la Ley 20/1990, de Régimen Fiscal de las Cooperativas introducidas en la ley 27/2015, del Impuesto sobre Sociedades}

Son dos las modificaciones realizadas por la ley 27/2015. Se trata en ambos casos de normas de ajuste que adaptan el régimen fiscal de las cooperativas a cambios operados por normas del régimen general.

La primera de ellas es la adaptación de la nueva regulación de la compensación de bases imponibles negativas prevista en el artículo 26 de la Ley del Impuesto sobre Sociedades, a la compensación a nivel de cuota con la que cuentan las cooperativas. El nuevo artículo 24 de la Ley 20/1990 prevé que, si la suma algebraica de las dos cuotas del ejer- 
cicio resultase negativa, ésta podrá compensarse por la cooperativa con las cuotas positivas de ejercicios posteriores, con el límite del $70 \%$ de la cuota íntegra previa a su compensación. En todo caso, se podrán compensar en el periodo impositivo cuotas íntegras por el importe que resulte de multiplicar un millón de euros al tipo medio de gravamen de la cooperativa.

La segunda es una adaptación del tratamiento fiscal otorgado a determinados activos por impuesto diferido, según la regulación prevista en el Real Decreto-Ley 14/2013, de 29 de noviembre, de Medidas Urgentes para la Adaptación del Derecho Español a la Normativa de la Unión Europea en Materia de Supervisión y Solvencia de Entidades Financieras ${ }^{13}$.

\section{La evolución de la regulación del régimen económico en la legislación cooperativa}

\subsection{Nuevos tipos de cooperativas que cuestionan la clasificación de cooperativas protegidas y especialmente protegidas}

Desde 1990 la tipología de cooperativas previstas en las leyes sustantivas ha experimentado importantes cambios. Quizás uno de los más destacados es la irrupción de cooperativas que no encajan en ninguno de los tipos previstos en las clasificaciones de las distintas leyes sustantivas.

La Ley estatal de cooperativas prevé doce clases de cooperativas distintas que pueden ser calificadas como de segundo grado, si estas se integran por cooperativas de la misma clase ${ }^{14}$. Como señala (Morillas

13 Ambas modificaciones están previstas en la Disposición Adicional Primera de la Ley $27 / 2014$.

14 El artículo 6 de la Ley 27/1999, de 16 de julio, clasifica las cooperativas:

1. Las sociedades cooperativas de primer grado podrán clasificarse de la siguiente forma:

- Cooperativas de trabajo asociado.

- Cooperativas de consumidores y usuarios.

- Cooperativas de viviendas.

- Cooperativas agroalimentarias.

- Cooperativas de explotación comunitaria de la tierra.

- Cooperativas de servicios.

- Cooperativas del mar.

- Cooperativas de transportistas.

- Cooperativas de seguros. 
Jarillo 2013,135$)^{15}$ la necesaria flexibilización de este régimen legal sobre la base de un catálogo limitado de tipos independientes, viene de la mano, fundamentalmente de la legislación autonómica. Se ha ido admitiendo la constitución de cooperativas que no se ajustan a ninguno de los tipos previstos, se permite la realización de actividades simultáneas que son propias de otras clases y se establece que, a las cooperativas ubicadas principalmente dentro de una clase, se les aplicarán las normas destinadas a otra que fueran compatibles. De esta forma, son muchas las leyes sustantivas que actualmente contemplan las cooperativas con objeto plural bajo las denominaciones de cooperativas integrales, cooperativas mixtas o cooperativas polivalentes ${ }^{16}$. La Disposición Adicional octava de la Ley de cooperativas estatal prevé que se considerarán especialmente protegidas las cooperativas integrales cuando, respecto a todas y cada una de sus actividades, se cumplan los requisitos exigidos para ser consideradas especialmente protegidas.

En nuestra opinión los beneficios fiscales reconocidos a las cooperativas deben ir directamente relacionados con el cumplimiento o desarrollo de actividades que promuevan los fines económicos y sociales previstos en la Constitución, para lo que debe exigirse el cumplimiento exclusivamente de requisitos que incidan sobre ellos.

Dichos incentivos fiscales deben ser compartidos con otras entidades que adopten formas jurídicas distintas, pero que persigan o coadyuven a la consecución de dichos objetivos. Las peculiaridades que presentan las cooperativas, inherentes a su forma jurídica, deben ser consideradas mediante normas de ajuste.

Otro cambio esencial es la regulación de las denominadas cooperativas sin ánimo de lucro, calificación que puede ostentar cualquier

- Cooperativas sanitarias.

- Cooperativas de enseñanza.

- Cooperativas de crédito.

2. Los Estatutos de las cooperativas de segundo grado podrán calificar a estas conforme a la clasificación del apartado anterior, siempre que todas las cooperativas socias pertenezcan a la misma clase, añadiendo en tal caso la expresión «de segundo grado».

15 (Morillas Jarillo 2013, 135).

16 La Ley 27/1999, de 16 de julio de cooperativas estatal regula en su artículo 105 las cooperativas integrales, definiéndolas en los siguientes términos: "Se denominarán cooperativas integrales aquéllas que, con independencia de su clase, su actividad cooperativizada es doble o plural, cumpliendo las finalidades propias de diferentes clases de cooperativas en una misma sociedad, según acuerdo de sus Estatutos y con observancia de lo regulado para cada una de dichas actividades. En dichos casos, su objeto social será plural y se beneficiará del tratamiento legal que le corresponda por el cumplimiento de dichos fines». 
cooperativa si cumple determinados requisitos. Se prohíbe que los resultados positivos que se produzcan en el ejercicio no sean distribuidos entre los socios, que el interés satisfecho por la cooperativa a las aportaciones de los socios al capital social no supere un interés superior al legal de dinero; se exige el carácter gratuito del desempeño de los cargos del Consejo Rector y que las retribuciones a socios de trabajo o trabajadores no superen el $150 \%$ de las retribuciones que se establezcan en convenio colectivo ${ }^{17}$.

La Ley 27/1999, de 16 de julio, de Cooperativas, es la que regula por primera vez dicha calificación, indicando que serán cooperativas sin ánimo de lucro aquellas que gestionen servicios de interés colectivo o de titularidad pública así como las que realicen actividades económicas que conduzcan a la integración laboral de las personas que sufran cualquier clase de exclusión social, siempre y cuando cumplan los mencionados requisitos.

De forma específica la ley contempla las cooperativas de iniciativa social, que por definición son cooperativas sin ánimo de lucro. Es difícil pensar en términos de ley estatal, en cooperativas sin ánimo de lucro que no sean cooperativas de iniciativa social, ya que estas a su vez pueden ser de cualquier clase. De manera que, cualquier clase de cooperativa que persiga los fines de interés general señalados y no distribuya beneficio a sus socios cumpliendo con los requisitos y prohibiciones que establece la ley, será una cooperativa sin ánimo de lucro. Las leyes autonómicas contemplan distintos tipos de cooperativas sin ánimo de lucro, en la línea de la ley estatal, entre ellas se encuentran las cooperativas de interés social, de integración social, de iniciativa social o de inserción ${ }^{18}$.

Al no ser consideradas entidades sin fines lucrativos no sólo no disfrutan del régimen fiscal previsto en la Ley 49/2002, para estas entidades y los posibles donantes o entidades colaboradoras, tampoco disfrutan de ningún incentivo al mecenazgo.

Por otra parte, la aplicación del régimen fiscal de las cooperativas no exenta de problemas al hallarnos ante un régimen fiscal pensando para cooperativas cuyo objetivo es proporcionar beneficios económicos a los socios. Entre otros, se plantean los siguientes problemas: $1 .^{\circ}$ No aparecen incluidas entre las cooperativas especialmente protegidas, sólo lo serán si adoptan la forma de cooperativa de trabajo asociado o de consumidores y usuarios. 2. ${ }^{\circ}$ Problemas relativos a la calificación

17 (Disposición Adicional Primera de la ley 27/1999 de cooperativas).

18 Sobre la tipología de las cooperativas que pueden ser calificadas según las leyes cooperativas, sin ánimo de lucro, véase (Montero Simó 2010, 164-171). 
de rendimientos obtenidos. ¿Qué calificación reciben los donativos o las cantidades que la cooperativa sin ánimo de lucro reciba de empresas fruto de acuerdos de colaboración? Las plusvalías que se obtengan por la transmisión de elementos afectos al desarrollo del objeto social deberían ser calificadas como cooperativas en vez de extracooperativas 3. Las cantidades destinadas a fondos irrepartibles distintos del fondo de reserva obligatorio o el fondo de educación y promoción no son deducibles en base imponible e incluso las cantidades que se destinen al fondo de educación y promoción que superen el 30 \% de los excedentes netos tampoco serán deducibles en base.

Sumando cambios experimentados por las leyes sustantivas a lo largo de estos años, encontramos la regulación de las denominadas microcooperativas en leyes como la de la Rioja y la de Castilla-La Mancha. Sólo se pueden considerar microcooperativas, cooperativas de trabajo asociado y de explotación comunitaria de la tierra ${ }^{19}$. El régimen fiscal especial de las cooperativas hace caso omiso a esta nueva calificación.

\subsection{Capital social y pasivo exigible}

El capital social de las sociedades cooperativas presenta importantes diferencias respecto al capital social de las sociedades mercantiles por multitud de motivos. Junto con el denominado capital estatutario, la cooperativa cuenta con un capital variable consecuencia de la entrada y salida de socios de la cooperativa, tal y como admite el principio de puerta abierta ${ }^{20}$, las aportaciones a capital deben ser reembolsadas al socio en caso de baja, a no ser que, si la ley cooperativa aplicable se lo permite, se rehúse al derecho de reembolso, aspecto sobre el que hemos hablado anteriormente. A ello hay que unir que dichas aportaciones pueden devengar intereses para el socio, con independencia del derecho del socio al retorno cooperativo.

El socio también puede encontrar otros cauces para financiar a la cooperativa mediante aportaciones que no forman parte del capital social. Se trata de aportaciones incorporadas al pasivo exigible, de distinta naturaleza: cuotas de ingreso o periódicas de los socios, títulos partici-

19 Artículo 72.2 y 4 de la Ley de cooperativas de la Rioja y artículos 2.3, 10.2, 11.3 y disposición final 2. ${ }^{a}$ de la Ley de cooperativas de Castilla-La Mancha y la Ley 6/2008, de 25 de junio de la Sociedad Cooperativa Pequeña de Euskadi.

20 Sobre los caracteres de las aportaciones al capital social de las cooperativas y sus diferencias con el capital social de entidades mercantiles véase, entre otros (Pendón Meléndez 2013, 553) y (Fernández Guadaño 2006, 40-61). 
pativos suscritos por socios o no socios, las participaciones especiales y los contratos de cuentas en participación.

Las leyes cooperativas contemplan los denominados títulos participativos; se trata de «instrumentos de financiación externa de las sociedades cooperativas que, a cambio de una aportación económica temporalmente predeterminada, no sólo proporcionan a sus titulares el derecho económico a obtener una remuneración en función de los resultados de la entidad, sino también ciertos derechos políticos como el de asistencia a la Asamblea General con voz pero sin voto» ${ }^{21}$.

Las participaciones especiales no están previstas en todas las leyes cooperativas. Se trata de deuda subordinada y en algún caso se prevé la posibilidad de que su vencimiento no tenga lugar hasta la aprobación de la liquidación de la cooperativa emisora. El objeto de estas participaciones es paliar los inconvenientes derivados de la variabilidad del capital social consecuencia del ingreso y baja de los socios. La mayoría de las leyes prevén un plazo de vencimiento mínimo de 5 años desde su emisión, plazo que coincide con el máximo de permanencia exigible a los socios 22 . Las participaciones otorgan a su titular un derecho de reembolso y un derecho a obtener remuneración prefijada; junto a ello otorgan ciertos derechos políticos, como el de asistencia a la Asamblea General o el de información, sin que a diferencia de los títulos participativos, ello les resulte inherente. Las participaciones pueden ser suscritas por socios o terceros y en alguna ley cooperativa se exige que el $50 \%$ de las participaciones sean objeto de una oferte preferente de suscripción para socios y trabajadores asalariados.

Por una parte, las cooperativas cuentan con participaciones a capital social que no determinan la participación en beneficios y los retornos se distribuyen en función de la actividad económica del socio; por otra, existen participaciones que no forman parte del capital social y conceden a sus titulares (que no tienen que tener la condición de socios) derechos políticos y cuya retribución depende de los resultados positivos del ejercicio. Estas últimas se califican como pasivo exigible y los intereses satisfechos como gasto deducible en el Impuesto sobre Sociedades.

21 (López Santana 2013, 631).

22 «...mediante la conjugación de ambas vías puede conseguirse robustecer la solvencia de la sociedad durante periodos temporales nada desdeñables e incluso, garantizar al menos en gran medida, la fijeza de u determinado importe en lo que se refiere a los fondos de los que puede disponer en cada momento la sociedad» (López Santana 2013, 637). 


\subsection{Operaciones con terceros ¿flexibilización en las normas sustantivas?}

La Ley 20/1990 incluye entre las causas de pérdida de la condición de cooperativa protegida previstas en el artículo 13, la realización de operaciones cooperativizadas con terceros fuera de los casos permitidos por las leyes cooperativas. Se trata de un primer límite al que se suma un segundo: En ningún caso podrá la cooperativa un volumen de operaciones con terceros superior al $50 \%$ del total de las operaciones que realiza la cooperativa. La propia norma admite que, con carácter excepcional la cooperativa puede necesitar realizar operaciones con terceros más allá del mencionado $50 \%$ sin perder su condición de cooperativa protegida siempre que cuente con la autorización por escrito, del Delegado de Hacienda ${ }^{23}$.

Desde el punto de vista de la tributación de los rendimientos de estas operaciones, no podemos olvidar que se trata de rendimientos extracooperativos que tributan al tipo general del impuesto. Según De Luis Esteban, «la Ley Fiscal considera tal posibilidad no como una situación normal cooperativa, tal y como parece presentarse en algunos casos por la doctrina, sino como excepción a un principio general que no altera de modo sustancial la esencia de la cooperativa, siempre que responda a una justificación objetiva generalizada a situaciones excepcionales previamente autorizadas» ${ }^{24}$. No podemos olvidar que uno de los objetivos de la Ley 20/1990 era desenmascarar a las «falsas cooperativas» y otorgar beneficios fiscales exclusivamente a aquellas que cumplieran con el principio mutualista. De hecho, al regular las causas de pérdida de la condición de cooperativa protegida, en el artículo 13, se está configurando el modelo de cooperativa que va a ser protegido fiscalmente. Las operaciones con terceros parecen constituir para parte de la doctrina una amenaza al principio mutualista y para otra una actividad necesaria para el sostenimiento de la cooperativa.

Si comparamos las leyes sustantivas vigentes con las anteriores, es evidente que han incrementado los límites de las operaciones con ter$\operatorname{ceros}^{25}$, lo que en nuestra opinión, responde al objetivo de flexibilización de las fuentes de financiación de las cooperativas.

23 Artículo 14 de la Ley 20/1990.

24 (De Luis Esteban 1996, 46).

25 Véase a modo de ejemplo, un cuadro en el que se distinguen cada una de las clases de cooperativa y se comprueba cómo ha aumentado el límite de las operaciones con terceros comparando la Ley General de cooperativas de 1987 y la ley 27/1999, (Alguacil Mari 2010, 968).

En países europeos como Francia, Italia y Portugal el conocido principio de exclusividad se plasma en la legislación sustantiva de forma muy distinta. Mientras que en Francia el artículo 3 de la Ley 1947 se establece prácticamente la exclusividad en las 
En nuestra opinión, la flexibilización del límite a las operaciones con terceros, por sí sola no cuestiona el principio mutualista, ni el tratamiento fiscal que debe otorgarse a las operaciones que la cooperativa realiza con socios. Cosa distinta es el tratamiento fiscal del resultado de estas operaciones, para cuya determinación debe tenerse en cuenta el destino de dichos rendimientos.

En el supuesto en que una cooperativa a la que se le aplique la ley estatal, opte por no contabilizar de forma separada los resultados extracooperativos de los cooperativos, al mantenerse el mismo porcentaje de dotación mínima a fondos obligatorios (artículo 57.4 Ley estatal) la distribución del beneficio económico al socio puede realizarse tanto por la vía del retorno como vía precio. Esta última circunstancia puede darse en aquellas comunidades autónomas en las que se admita el valor real de las operaciones que la cooperativa realiza con sus socios.

Si el socio se beneficia económicamente de forma directa, percibiendo retornos del resultado de operaciones con terceros. Dicho resultado debe gravarse al tipo general.

Aspectos como la limitación de operaciones con terceros, el obligatorio destino de los resultados de dichas operaciones a fondos irrepartibles y por lo tanto, la inaccesibilidad de los socios a dichos beneficios, así como la contabilización separada de los resultados como método garante de los anteriores presupuestos, constituyen aspectos esenciales de la cooperativa a los que obedece, sin lugar a dudas, el régimen fiscal vigente.

En las leyes cooperativas, la regulación de muchos de estos aspectos ha cambiado. No podemos hablar de un modelo de cooperativa uniforme en las distintas leyes cooperativas, ni tan siquiera podemos hablar de un solo modelo de cooperativa en cada una de ellas ${ }^{26}$.

operaciones con socios, con algunas excepciones, en Italia y Portugal se debe operar básicamente con socios pero no se establece expresamente un límite concreto.

26 Autores como (Alonso Rodrigo 1999: 293-309) (Alguacil Mari 2001: 915-986) (Vicent Chuliá 1998: 7-33) entre otros, advierten de la posible desmutualización o aproximación al modelo patrimonial de la sociedad cooperativa, con evidentes consecuencias en el tratamiento tributario de estas entidades. Según (Alonso Rodrigo 1999, 295-300), las normas cooperativas más recientes potencian y facilitan la posición competitiva de la cooperativa en el mercado, relegando a un segundo plano e incluso sacrificando en gran medida los principios cooperativos y los valores sociales que siempre caracterizaron a este modelo societario y se encuentran en el fundamento último de su nacimiento. La medidas adoptadas por la Ley estatal de cooperativas que favorecen la generación de lucro para la cooperativa y para sus socios son: a) posibilidad de repartir entre socios resultados obtenidos de operaciones con terceros; b) elevación del límite del interés de las aportaciones al capital; c) contabilización conjunta unida al incremento de la dotación a Fondos de reservas obligatorios; d) repartibilidad parcial del FRO; e) ampliación de las aplicaciones del FEP. 


\section{Reformas del régimen fiscal de las cooperativas en territorios forales vascos. El tipo mínimo de gravamen para las cooperativas}

Los territorios forales vascos cuentan con sus propias normas sobre fiscalidad de las sociedades cooperativas ${ }^{27}$ que se apartan del régimen previsto en la norma estatal. Las modificaciones experimentadas en las normas forales desde 1990 han sido de calado. A día de hoy, ofrecen un régimen fiscal más acorde con la regulación sustantiva. Pasamos a describir algunas de las peculiaridades.

1. En la clasificación de las cooperativas especialmente protegidas, Incluyen las cooperativas de enseñanza.

2. No admiten la deducibilidad de las cantidades destinadas a retribuir participaciones especiales que tengan la consideración de capital social, cuyos titulares no sean socios o asociados.

3. Las cantidades que las cooperativas aporten a las instituciones de cooperación intercooperativa destinadas al saneamiento financiero o a la promoción y desarrollo de nuevas cooperativas o de nuevas actividades serán deducibles en la base imponible. Para ello es necesario que la Administración Tributaria expresa y previamente a la aportación haya reconocido tal carácter a la mencionada institución.

4. No existe la diferenciación de resultados cooperativos y extracooperativos. Se aplica un tipo único reducido. Aunque existen dos bases imponibles, general y especial.

5. Prevén un tipo reducido del $18 \%$ para las cooperativas microempresas y un tipo del $21 \%$ con carácter general.

6. Respecto a los mecanismos para evitar la doble imposición de los retornos percibidos por cooperativas, prevén una exención cuando la cooperativa que los distribuye es cooperativa protegida y en el supuesto en que sea especialmente protegida la exención será tan sólo del $50 \%$ del importe del retorno ${ }^{28}$.

27 Norma foral 9/1997, de 14 de octubre, sobre Régimen Fiscal de las Cooperativas en Bizkaia, Norma foral 16/1997, de 19 de junio, sobre Régimen Fiscal de las Cooperativas en Álava y Norma foral 2/1997, de 22 de mayo, sobre Régimen Fiscal de las Cooperativas de Gipuzkoa.

28 El artículo 24 apartado 1 de las tres normas forales sobre régimen fiscal de las cooperativas, se remite al artículo 33 apartado 1 y 2 de la Norma foral impuesto sobre Sociedades en los que se prevé una exención del $100 \%$ del dividendo de fuente interna o un $50 \%$ respectivamente. En este último caso, el contribuyente deberá incluir en la base imponible el 50 por 100 de su importe. 
7. Las cooperativas especialmente protegidas cuentan con una deducción del $50 \%$ de la cuota líquida, en vez de una bonificación sobre la cuota íntegra.

8. ${ }^{\circ}$ Respecto a las causas de pérdida de la condición de cooperativa protegida, en lo relativo a las operaciones con terceros no socios, incluyen la realización de operaciones con terceros fuera de los casos permitidos por las leyes. No se establece un límite específico, a diferencia de Ley 20/1990, relativo al 50\% del volumen total de las operaciones realizadas por la cooperativa.

9. Los límites de participación en entidades no cooperativas son superiores a los de la Ley 20/1990, son del $25 \%$ el general y del $50 \%$ cuando se trate de entidades que ejerzan actividades preparatorias, complementarias o subordinadas a las de la cooperativa.

10. A las cooperativas de utilidad social y de iniciativa pública se les aplican las normas forales de régimen fiscal de entidades sin fines lucrativos e incentivos fiscales al mecenazgo. También se aplican los incentivos fiscales previstos en esa norma a los donativos o convenios de colaboración.

Junto a las diferencias señaladas, las normas forales han importado de la regulación del impuesto sobre sociedades prevén la existencia de una cuota efectiva y la consiguiente tributación mínima, tanto para las sociedades en régimen general ${ }^{29}$ como para las sociedades cooperativas. Con ello se limita la aplicación de bonificaciones y deducciones en el ejercicio garantizando una cuota mínima. La cuota efectiva es igual a la base imponible por el tipo efectivo de gravamen.

Ello implica que, salvo por las deducciones de I+D+i, la aplicación de deducciones sobre la cuota no puede dar lugar a que la cuota efectiva sea con carácter general, inferior a un tipo de gravamen «mínimo» que se aplica sobre la base imponible.

En las tres normas los tipos de gravamen del impuesto sobre sociedades, general y aplicable a micro y pequeñas empresas, son el $28 \%$ y el $24 \%$ respectivamente, siendo el tipo de tributación mínima general el $13 \%$, el aplicable a pequeñas y microempresas el $11 \%$, el de entidades parcialmente exentas el $9,75 \%$ y el de entidades de hidrocarburos el

${ }^{29}$ Artículo 59 de la Norma Foral del Impuesto sobre Sociedades 11/2013, de 5 de diciembre, de Bizcaia. Artículo 59 de la Norma Foral del Impuesto sobre Sociedades 37/2013, del 13 de diciembre, de Álava.

Artículo 59 de la Norma Foral del Impuesto sobre Sociedades 2/2014, de 17 de enero, de Guipuzkoa. 
16,25\%. También prevén un tipo reducido de tributación mínima para el supuesto en que las empresas mantengan o incrementen su promedio de plantilla laboral con carácter indefinido respecto al del ejercicio anterior igual al $11 \%, 9 \%, 7,75 \%$ y $14,25 \%$ en cada uno de los casos anteriores.

El alcance de esta nueva regla es limitado ya que no afecta a la eliminación de la doble imposición económica ni a los incentivos fiscales vinculados a la dotación de reservas indisponibles ya que ambos operan en la base imponible. Por otra parte, tampoco afecta a la deducción por I+D+i que se aplica después de la tributación mínima y puede absorber la totalidad de la cuota líquida.

Las deducciones que se pueden ver afectadas por la tributación mínima son la deducción por inversiones en activos no corrientes, la deducción por inversiones y gastos vinculados a proyectos de desarrollo sostenible, conservación y mejora del medioambiente y aprovechamiento de fuentes de energía, deducción por creación de empleo y deducción por producciones cinematográficas. Hay que tener en cuenta que estas deducciones cuentan con una limitación en cuota específica; no pueden superar el $45 \%$ de la cuota líquida, ello implica que en ningún caso el tipo nominal puede ser inferior a un $55 \%$ del mismo, por ejemplo el tipo del $28 \%$ aplicando el límite del $45 \%$ no podría ser inferior a un $15,4 \%$. Si el tipo mínimo para sociedades que tributan al $28 \%$ es el $13 \%$, éste solo operará cuando las mencionadas deducciones concurran con la deducción para evitar doble imposición internacional, lo que nos hace pensar en una eficacia limitada.

Las cooperativas también cuentan con tributación mínima. En términos generales, la tributación de las cooperativas en las normas forales de los territorios vascos, presentan diferencias importantes respecto a la Ley 20/1990. Entre otras, se prevé una base imponible general integrada por prácticamente todos los rendimientos, en la que se incluyen tanto rendimientos cooperativos como resultados extracooperativos. La otra base imponible, la denominada especial está constituida por rendimientos de capital mobiliario (artículo 13 bis).

Las cooperativas protegidas cuentan con dos tipos de gravamen reducidos aplicables a la base imponible general, el $20 \%$ y para las cooperativas microempresas el $18 \%$, siendo la cuota efectiva en el primer caso es de un $9 \%$ y en el segundo de un $8 \%$. Estos porcentajes se ven reducidos a un 7\% y $6 \%$ respectivamente, si la cooperativa mantiene o incrementa su promedio de plantilla laboral con carácter indefinido respecto al ejercicio anterior.

La aplicación de la tributación mínima, aunque ya hemos dicho que presenta un alcance limitado, tiene especial incidencia en las cooperativas especialmente protegidas que cuentan con una deducción en la 
cuota igual al 50\% de la cuota líquida. Hasta 2014 (se modifica la Norma Foral 2/1999), las cooperativas especialmente protegidas contaban con la bonificación en la cuota que ha sido sustituida por una deducción.

La deducción, a diferencia de lo que ocurre con la bonificación en la cuota prevista en la Ley 20/1990, se calcula sobre el importe de cuota líquida. La cuota efectiva no podrá ser inferior al $9 \%$ de la base imponible general. Teniendo en cuenta que las deducciones generales también aplicables a las cooperativas podrían minorar la cuota hasta dejarla en un 55\%, y que esa cuota se reduciría en un 50\% (por la mencionada deducción de las cooperativas especialmente protegidas) la cuota se podría reducir en ese caso hasta un 25,5\%; ello implicaría que el tipo de gravamen efectivo sería un 5,1\%. En el supuesto en que se aplicaran deducciones para evitar la doble imposición internacional todavía el tipo de gravamen efectivo sería aún más bajo.

\section{Conclusiones y propuestas para una reforma}

Es casi unánime en la doctrina la opinión de que el régimen fiscal de las cooperativas debe ser objeto de revisión. Como señala (Tejerizo López 2010: 69) «el régimen fiscal de las cooperativas ya no es tan favorable como pudo serlo en 1990, sobre todo porque la tributación de las sociedades en España se ha aligerado hasta equipararse casi a la de las sociedades. Más aun, en algunos extremos sería más beneficioso para ellas que se les aplicara el régimen general, sobre todo el de las empresas de reducida dimensión dentro de cuyos parámetros se encuentran la mayoría de ellas». La perdurabilidad de la Ley 20/1990 no significa que el texto mantenga hoy en día el mismo alcance que cuando entró en vigor; todo lo contrario los incentivos fiscales previstos han perdido con el paso del tiempo su eficacia inicial (Rodrigo Ruiz 2010: 15).

La reforma del régimen fiscal de las cooperativas puede plantearse bien como una adaptación de la ley vigente a los cambios operados en el régimen general del impuesto sobre sociedades en los términos que hemos planteado en epígrafes anteriores ${ }^{30}$ o bien como una auténtica reforma que modifique los aspectos básicos del régimen actual.

30 Hemos planteado la necesaria revisión del tipo de gravamen, la aplicabilidad de las reducciones por reserva de capitalización y de nivelación, la modificación de la aplicación de la norma de valoración de las operaciones de la cooperativa con sus socios, la reducción de las causas de pérdida de la condición de cooperativa protegida, la revisión de las actuales cooperativas especialmente protegidas y la aplicación del régimen especial para entidades sin fines lucrativos a las cooperativas sin ánimo de lucro. 
Esa reforma debería asentarse en primer lugar, en el mandato de fomento del artículo 129.2 de la Constitución cuyo desarrollo cuenta con un claro límite: la prohibición de que el Estado español otorgue ayudas de Estado selectivas a las cooperativas ${ }^{31}$. El mandato de fomento no se traduce de forma necesaria en beneficios fiscales, de forma ineludible la norma tributaria debe reconocer las peculiaridades de la cooperativa frente a otras formas sociales y efectuar la consiguiente adaptación de la normativa general del Impuesto sobre Sociedades, a estas entidades.

En segundo lugar, las cooperativas deberían disfrutar de los beneficios fiscales aplicables a entidades con las que compartan características y objetivos. Beneficios fiscales que no deben venir determinados por la forma jurídica sino por los objetivos constitucionales y comunitarios que se materialicen en estas y otras entidades.

En este sentido, consideramos que el régimen fiscal debe descansar en normas de ajuste que constituyan un suelo común a todas las cooperativas y en beneficios fiscales compartidos con otras entidades (de reducida dimensión o con las que compartan objetivos constitucionales, como es la creación de empleo, la participación de los trabajadores en los medios de producción, etc.).

Si atendemos al contexto europeo, el tratamiento fiscal otorgado en los distintos estados miembros no es homogéneo. Respecto a las normas de ajuste del Impuesto sobre Sociedades, que afectan al beneficio cooperativo, siguiendo a (Alguacil Mari 2001, 138-150) podemos agrupar las soluciones adoptadas por los distintos sistemas tributarios europeos, en cuatro grandes bloques: $1 .{ }^{\circ}$ Aquellos regímenes que aplican a las cooperativas el régimen general del Impuesto sobre Sociedades, sin tener en cuenta sus peculiaridades, como es el caso de Irlanda y Austria; $2{ }^{\circ}$ Los que aplican el método de exención en la cooperativa de los resultados obtenidos con socios. La exención se combina, bien con un sistema de transparencia fiscal o de imputación de resultados

31 Según (Hinojosa Torralvo 2010: 88), «si las cooperativas consiguen alcanzar cotas de competitividad elevadas con otros operadores económicos, el estado actual de la Unión Europea no les permitirá otra cosa que plegarse a las consecuencias de competencia neutral. En un escenario de competencia neutral habría que replantearse las limitaciones inherentes a la esencia misma de los regímenes jurídico y económico propios de esta entidades, pues difícilmente lo que las regulan actualmente podrán dotarlas de la agilidad que se precisa para competir de hecho en igualdad de condiciones. Una alternativa razonable es la de dotar de una vez por todas a las entidades de economía social de un régimen que las distinga en lo que tienen de distinto y que sea lo suficiente claro y preciso - y aun comprometido- como para ser aceptado pacíficamente y no puesto continuamente en cuestión». 
a los socios o bien, con la tributación por parte del socio del beneficio percibido vía dividendo. Se suele dar sólo para determinadas cooperativas, en países como Grecia, Alemania, Portugal, entre otros. 3. ${ }^{\circ}$ Los que deducen el retorno de la base imponible de la cooperativa como ocurre en Italia y Gran Bretaña para las cooperativas que se acogen a la Industrial and Provident Societies Act y $4 .^{\circ}$ Los que conceden a los beneficios distribuidos, el tratamiento de dividendo y aplican a la cooperativa un tipo de gravamen más bajo, entre los que se encuentran España y Portugal.

Proponemos como elementos configuradores de una posible reforma ${ }^{32}$, entre otros, los siguientes:

1. ${ }^{\circ}$ El régimen especial de las sociedades cooperativas debe descansar en normas de ajuste que reconozcan la necesaria adaptación del impuesto sobre sociedades a estas sociedades.

2. Eliminación de la clasificación fiscal existente. Las normas de ajustes deberán aplicarse a toda cooperativa y los beneficios fiscales deberán aplicarse en función de las características que compartan con otras entidades de la economía social o sociedades mercantiles, pudiendo tratarse de características relativas al tamaño de la cooperativa o al papel que ésta juega en la consecución de objetivos constitucionales (creación de empleo, protección de los consumidores, fomento de los modelos empresariales de participación de los trabajadores en los medios de producción, necesaria capitalización etc. $)^{33}$.

3. La norma fiscal sólo debe exigir aquellos requisitos que justifiquen la norma de ajuste aplicable o el beneficio fiscal concreto. Por ejemplo, para admitir la deducibilidad de las cantidades destinadas a fondos de reserva obligatorios, se debería exigir que la cooperativa cumpla con las dotaciones legales y además, que esos fondos sean irrepartibles. El incumplimiento de los requisitos no debe implicar la expulsión del régimen fiscal, tan sólo debe implicar la pérdida del derecho a aplicar la norma de ajuste.

32 Parte de las propuestas que se formulan se recogieron en un informe realizado por un grupo de trabajo de CEPES-España en 2008 al que pertenecía la autora de este artículo. Puede consultarse en http://www.agro-alimentarias.coop/ficheros/doc/02727. pdf

33 Para (Pastor Del Pino 2012: 98) hace falta replantearse la justificación de un trato fiscal diferenciado en función, exclusivamente, del tipo o modelo social. 
4. ${ }^{\circ}$ No debe tributar en la cooperativa el beneficio que esta obtenga de las operaciones con socios y de las directamente relacionadas con éstas.

El régimen fiscal especial vigente descansa en la tributación a tipo reducido del rendimiento de operaciones cooperativizadas, fundamentalmente operaciones con socios, en la tributación del rendimiento de las operaciones con terceros al tipo general del impuesto y en el caso de las cooperativas especialmente protegidas de una bonificación en la cuota del $50 \%$.

Es importante tener en cuenta, en primer lugar, que hay muchas cooperativas que son simplemente protegidas o incluso no protegidas fiscalmente y en segundo lugar, que en la bonificación actual del $50 \%$ de la cuota íntegra, aplicable sólo a las cooperativas especialmente protegidas, subyace la lógica de la no tributación de los resultados de operaciones con socios. Si observamos, la propia Ley 20/1990 establece que las operaciones con terceros no pueden superar en ningún caso el $50 \%$ del volumen total del operaciones, lo que en cierto modo, nos está indicando que un 50\% de la cuota íntegra, que como mínimo procederá de operaciones con socios, no va a tributar. Es cierto que se permite compensar la cuota íntegra cooperativa con la cuota íntegra extracooperativa, en el caso en que alguna sea negativa, pero esta compensación, no modifica la conclusión anterior. Lo que implica para la cooperativa es un diferimiento de impuesto vía anticipación de compensación con cuotas positivas de ejercicios posteriores.

El retorno cooperativo, en la parte en que no proceda de operaciones con terceros, debe ser gasto deducible. Creemos que esta medida debe constituir el centro de la fiscalidad de las cooperativas en el Impuesto sobre Sociedades ${ }^{34}$.

El retorno distribuido, como ocurre en Italia, se concibe como devolución de parte del precio de los bienes o servicios adqui-

34 (Rodrigo Ruiz 2010, 21) propone «declarar exentos en el impuesto sobre sociedades a los retornos cooperativos y un tipo de gravamen reducido, por cuanto la Comisión Europea parece reconocer que estas percepciones, en razón de su carácter mutual, pueden limitar su tributación a la que corresponda en la imposición personal de los socios perceptores (donde en ningún caso deberían gravarse los retornos no distribuidos imputables a los socios)». Considera que de "esta manera se tendrían en cuenta de un lado, por vía de exención, los rasgos específicos inherentes a la mutualidad, mientras el tipo de gravamen reducido compensaría por otro, la carga patrimonial añadida que la irrepartibilidad de los fondos conlleva, a la par que permitiría introducir también, superando la mera compensación, una medida de auténtico fomento». 
ridos por el socio o una mayor remuneración de las aportaciones realizadas por éste ${ }^{35}$, por lo que debería tributar en el IRPF del socio como renta de idéntica naturaleza a la recibida por las operaciones que el socio realiza con la sociedad.

5. ${ }^{\circ}$ Consecuencia de lo anterior es la eliminación del doble tipo de gravamen y de la consiguiente fragmentación de la base imponible. La cooperativa debería tributar al tipo general del 25\% o al 15\% aplicable a las sociedades de nueva creación, en su caso.

6. ${ }^{\circ}$ Respecto a la deducción de las cantidades destinadas al Fondo de Educación y Promoción deberían seguir constituyendo gasto deducible y ampliarse la reducción en base imponible al 100\% de las cantidades destinadas al Fondo de reserva obligatorio siempre que este sea irrepartible o en la proporción en que lo sea.

7. Las operaciones que la cooperativa realice con sus socios en el desarrollo de sus fines sociales se valorarán según el precio que efectivamente se haya pagado. La norma fiscal no debería permitir la no tributación de los beneficios de las operaciones con terceros, que se podría producir al traspasar el beneficio de dichas operaciones vendiendo a los socios por debajo del coste o comprándole a éstos con pérdidas

Consideramos que, si bien se debe admitir el precio efectivo por el que la operación se haya realizado, éste debe limitarse en dos sentidos. Cuando la cooperativa preste un servicio o suministre bienes al socio, el precio no podrá ser inferior al coste de tales servicios o suministros, incluida la parte correspondiente de los gastos generales de la entidad. En el caso en que la cooperativa sea la que pague el bien o servicio recibido, el precio no podrá ser superior a los precios de venta obtenidos menos los gastos directos e indirectos para la gestión de la cooperativa. En nuestra opinión, es la ley cooperativa aplicable y las normas contables las que deben determinar si la cooperativa tiene o no que valorar estas operaciones a valor de mercado.

35 Sobre el régimen fiscal de los retornos en Italia, véase (Maurizio Messina 2010, 119-134). 


\section{Bibliografía}

ALGUACIL MARI, Pilar. 2014. «El tratamiento en el impuesto sobre sociedades del fondo de educación y promoción de las cooperativas», Quincena Fiscal, n. ${ }^{\circ} 12: 21-41$.

ALGUACIL MARÍ, Pilar 2003. "Tratamiento fiscal de las cooperativas a la luz del régimen europea de ayudas de Estado CIRIEC-España, Revista de Economía pública, social y cooperativa, n. ${ }^{\circ} 14: 131$.

ALGUACIL MARI, Pilar. 2001. "Beneficios tributarios de las cooperativas tras la Ley estatal 27/1999», Revista de Derecho Financiero y de Hacienda Pública, núm. 262: 915-986.

ALONSO RODRIGO, Eva. 1999. "Reflexiones sobre las posibles implicaciones fiscales de la nueva legislación cooperativa», Boletín Asociación Internacional de Derecho cooperativo, vol. I, núm.32: 293-309.

ARANA LANDÍN, Sofia. 2011. «El régimen fiscal de las cooperativas españolas en la Unión Europea: conclusiones para las líneas de reforma del cooperativismo español», Gezki n. ${ }^{\circ}$ 7:77-98.

ARANA LANDÍN, Sofía. 2010. «La nueva regulación sobre operaciones vinculadas y su incidencia en las cooperativas», CIRIEC-España. Revista de Economía Pública, Social y Cooperativa, n. ${ }^{\circ}$ 69: 135-159.

BAHÍA ALMANSA, Belén. 2012. "El régimen fiscal especial de las cooperativas y su compatibilidad con la normativa sobre ayudas de Estado», CIRIEC-ESpaña, Revista jurídica n. ${ }^{\circ} 23:$ 151-180.

DE LUIS ESTEBAN, José Manuel. 1996. «El impuesto sobre sociedades y la fiscalidad de las cooperativas: Reforma y continuidad», CIRIEC-España. Revista de Economía Pública, Social y Cooperativa, n. ${ }^{\circ 23: ~ 33-46 . ~}$

DURÁN-SINDREU BUXADÉ, Antonio. 1989. «Delimitación conceptual en el ámbito tributario de los retornos cooperativos», Civitas. Revista Española de Derecho Financiero, n. ${ }^{\circ}$ 61: 51-66.

FERNÁNDEZ GUADAÑO, Josefina. 2006. «Diferentes consideraciones entorno al capital social de las sociedades cooperativas», REVESCO. Revista de Estudios Cooperativos, n. ${ }^{\circ} 88: 40-61$.

HERRERO BLASCO, Aurelio. 2015. «El ahorro fiscal de las cooperativas en el Impuesto sobre Sociedades en España». CIRIEC-España, Revista de Economía Pública, Social y Cooperativa 84: 279-300.

HINOJOSA TORRALVO, Juan José. 2010. "Fiscalidad y financiación de las cooperativas ¿A qué juega la Unión Europea? CIRIEC-España, Revista de Economía Pública, Social y Cooperativa, n. ${ }^{\circ}$ 69: 73-90.

LÓPEZ SANTANA, Nieves. 2013. «Régimen económico», Tratado de Derecho de cooperativas, Tomo I, 624-642, Valencia: Tirant Lo Blanch.

MAURIZIO MESSINA, Sebastiano. 2010. «Perfiles del régimen fiscal italiano de las cooperativas», CIRIEC-España. Revista de Economía Pública, Social y Cooperativa, n. ${ }^{\circ}$ 69: 119-134.

MONTERO SIMÓ, Marta. 2010, «La fiscalidad de las cooperativas sin ánimo de lucro», CIRIEC-España, Revista de Economía Pública, Social y Cooperativa, n. ${ }^{\circ}$ 69: 161-190. 
MONTERO SIMÓ, Marta. 2007. «Régimen fiscal de las sociedades cooperativas. Cuestiones en revisión». Civitas. Revista Española de Derecho Financiero, n. ${ }^{\circ}$ 135: 627-684.

MONTERO SIMÓ, Marta. 2005, Análisis jurídico-tributario de la sociedad cooperativa, Bilbao: Desclée De Brower.

MORILLAS JARILLO, M. ${ }^{a}$ José. 2013, "Concepto y clases de cooperativas», Tratado de Derecho de Cooperativas, tomo I, Tirant Lo Blanch, p. 135-139.

PANIAGUA ZURERA, Manuel y Jiménez Escobar, Julio. 2014. «La necesidad de una legislación cooperativa adecuada: aspectos mercantiles, tributarios y de Derecho comunitario», CIRIEC-España, Revista de Economía Pública, Social y Cooperativa, n. ${ }^{\circ} 81:$ 61-93.

PASTOR DEL PINO, Carmen. 2012. "Competitividad de las cooperativas y régimen fiscal específico: el incentivo por objetivos», CIRIEC-España, Revista jurídica n. ${ }^{\circ}$ 23: 97-120.

PENDÓN MELÉNDEZ, Miguel Angel. 2013. «Régimen económico», Tratado de Derecho de cooperativas, Tomo I, 553-560. Valencia: Tirant Lo Blanch.

POLO GARRIDO, Fernando y Sarasa Cortina, Cristina. 2013. "Las operaciones vinculadas y las operaciones cooperativizadas bajo normas internacionales de información financiera, reflexiones para el marco contable español», CIRIEC-España, Revista de Economía Social, Pública y Cooperativa, n. ${ }^{\circ}$ 77: 87-107.

RODRIGO RUIZ, Marco Antonio. 2010, "Consideraciones sobre el régimen fiscal de las cooperativas. Problemas actuales y líneas de reforma», CIRIECEspaña, Revista de Economía Pública, Social y Cooperativa, n. ${ }^{\circ}$ 69: 9-26.

TEJERIZO LÓPEZ, José Manuel. 2010. "Algunas reflexiones sobre el régimen fiscal de las cooperativas», CIRIEC-España, Revista de Economía pública, social y cooperativa, núm. 69: 53-71.

VICENT CHULIÁ, Francisco. 1998. "Mercado, principios cooperativos y reforma de la legislación cooperativa», CIRIEC-España, Revista de Economía Pública, Social y cooperativa, núm.29: 7-33.

Informe realizado por un grupo de trabajo de CEPES-España. 2008. Consultado en mayo de 2016. http://www.agro-alimentarias.coop/ficheros/ doc/02727.pdf

Comunicación de la Comisión al Consejo, al Parlamento Europeo, al Comité Económico y social europeo y al Comité de las regiones sobre el fomento de las cooperativas en Europa. Bruselas, 23.2.2004, COM (2004) 18 final. http://eur-lex.europa.eu/legal-content/ES/ TXT/?uri=celex\%3A52004DC0018 


\section{Derechos de autor}

El Boletín de la Asociación Internacional de Derecho Cooperativo es una revista de acceso abierto lo que significa que es de libre acceso en su integridad inmediatamente después de la publicación de cada número. Se permite su lectura, la búsqueda, descarga, distribución y reutilización legal en cualquier tipo de soporte sólo para fines no comerciales y según lo previsto por la ley; sin la previa autorización de la Editorial (Universidad de Deusto) o el autor, siempre que la obra original sea debidamente citada (número, año, páginas y DOI si procede) y cualquier cambio en el original esté claramente indicado.

\section{Copyright}

The International Association of Cooperative Law Journal is an Open Access journal which means that it is free for full and immediate access, reading, search, download, distribution, and lawful reuse in any medium only for non-commercial purposes, without prior permission from the Publisher or the author; provided the original work is properly cited and any changes to the original are clearly indicated. 